\title{
Analysis of Policy Responses to COVID-19: A Qualitative Study in Northern Iran
}

\section{Zeynab Farhadi}

Babol University of Medical Science

Morteza Salemi

Lorestan University of Medical Sciences

Mohammad Ali Jahani ( $\nabla$ drmajahani@yahoo.com )

Babol University of Medical Science https://orcid.org/0000-0001-8329-2632

\section{Research}

Keywords: COVID-19 Pandemic, Health Policy, Policy Making, Disease Outbreaks

Posted Date: August 3rd, 2021

DOI: https://doi.org/10.21203/rs.3.rs-682814/v1

License: (c) (i) This work is licensed under a Creative Commons Attribution 4.0 International License. Read Full License 


\section{Abstract \\ Background}

Preparation and financing of treatments, control of disease by limited resources, capacity building for the research and development related to the spread of disease, and measures to prevent and control the infection are known as the most important challenges encountered by the policy-makers involved in an epidemic outbreak. Therefore, the present study was conducted to analyze the policy responses of Babol University of Medical Sciences (BUMS) to Coronavirus (COVID-19).

\section{Methods}

For this purpose, a qualitative study was performed to investigate the policy responses of BUMS to COVID-19 in Babol (northern Iran) from the beginning of January to the end of March, 2021. The statistical population included the experts, pundits, policy-makers and planners involved in four areas of management, treatment, healthcare, and health donation. Data collection was done according to interviews and policy documents, and the obtained data were analyzed based on the Walt and Gilson's policy triangle framework.

\section{Results}

Interviews and policy documents were determined after several stages of review according to the Walt and Gilson's policy triangle framework, and the main themes were determined as: policy context, policy analysis, policy-making process, actors and stakeholders, and ways to deal with COVID-19 outbreak. Each theme was divided into 18 sub-themes. Finally, the related topics were extracted from the sub-themes.

\section{Conclusions}

Considering the large number of patients waiting for treatment, most of the decisions and policies were directed to their treatment, and the subject of prevention was at the second priority of policy making. Moreover, there was no practical program or policy for tracking the asymptomatic carriers in the community.

\section{Contributions To The Literature}

1. Treatment of the Covid-19 pandemic, more than any other disease, required action at various levels of society.

2. The support and empathy of the city's benefactors along with health system policymakers played an important role in motivating health care providers. 
3. The presence of the University of Medical Sciences in the city was a great help in controlling Covid19 pandemic.

\section{Background}

According to the World Health Organization's (WHO) report on May 14, 2021, a total of 2,722,007 people has been infected with COVID-19 in Iran and 76,231 of them have lost their lives so far (1). The first case was officially found in China in early December 2019 (2). The official CDC data from China showed that the COVID-19 pandemic could cause more infection and death compared to SARS or MERS, and most of the infected people, without any symptom or with mild symptoms, were able to release the virus and transmit it to others. Therefore, preventing the spread of COVID-19 is highly challenging and requires a strict monitoring (3). It is noteworthy that the therapeutic strategies to combat the infection have only been of supportive types and prevention has proved to be the best weapon to reduce transmission in the society (4).

To control the COVID-19 pandemic, the current world leaders have sought to implement the best practice using a variety of strategies (5) and take the proper countermeasures to reduce the destructive effects of COVID-19 (4). In Iran, after the diagnosis of the first case of COVID-19 on February 19, 2020 in Qom, despite the heavy political sanctions against providing the medical equipment and life-saving medications to deal with emergencies, implementation of the appropriate policies was put on the agenda as a general principle (2-6). Therefore, as in other countries, it was attempted to increase the capacities by strengthening the primary healthcare and social supports (7) and prioritizing the actions of the health system in order to make the best use of the available resources in Iran (6). In such cases, the most important challenges encountered by the policy-makers are making preparations and providing finance for the outbreak in a complex political environment with limited resources, balancing the investments in public health and health services, creating the capacity for research and development concerning the outbreak, and prevention and control of infection and (8). By tackling these challenges, the policy-makers would be able to establish the policies required for confronting the social problems and solve the problems caused by the previously adopted policies (9).

Babol, located in Mazandaran province (northern Iran), has been in the red zone since the onset of the pandemic in Iran. Due to having several university hospitals, this city has hosted many patients from the nearby cities. COVID-19 has posed several challenges to Babol University of Medical Sciences (BUMS) from the very beginning. Given the role of policy-making and its impact on cost control and success or failure of the health systems, scientific and systematic policy analyses are essential (10). Policy analysis can provide a clear picture of how and why the effective policies are developed and implemented over time (11). Therefore, the present study was conducted to analyze the policy responses of BUMS to COVID-19 from January to March, 2021.

\section{Methods}


A qualitative study was conducted to explore the policy responses of BUMS to COVID-19 from the beginning of January to the end of March, 2021 in Babol (Iran). Understanding of the textual data can lead to drawing a valid inference from the data related to the research objectives (12). The Walt and Gilson's policy triangle framework, which provides a systematic model for data management and mapping, was used to interpret the obtained data (13-15) (see additional file 1). The Walt and Gilson's framework can help researchers in systematic understanding and analysis of the health-related policies. This framework consists of four elements: context (why), content (what), process (how), and actors (who). Walt and Gilson argue that health policy-making is an interactive process in a specific social, economic, and cultural context in which actors are at the center of the process (16).

The statistical population used in this study included the experts, pundits, policy-makers and planners involved in four areas of management, treatment, healthcare and health donation. To maintain the privacy, all the participants were mentioned based on their specialization. Moreover, the criterion for entering the interview was participation in at least 15 meetings of the COVID-19 crisis committee in BUMS (see list of interview participants based on their skills additional file 2). The interviews were conducted after ethical approval and obtaining the ethics code No. 724133083 and a letter of introduction from the Deputy of Research and Technology of the university. Finally, the interviews and the policy documents (by laws, procedures, instructions, minutes and flowcharts) were analyzed (17).

To analyze the data, the text of the interviews was studied several times in order to gain a comprehensive understanding of them (see interview guide additional file 3 ). All the interviews and decisions of the COVID-19 crisis committee were analyzed and coded as units of analysis. Paragraphs and sentences or words were also considered as semantic units. Then, the semantic units were abstracted, conceptualized and coded according to their hidden concepts. The codes were compared with each other in terms of their similarity and difference and classified into more abstract classes using specific labels (12). The revision technique was used to increase the validity of the data. For this purpose, at the end of each interview, the participant was provided with a summary of his/her statements to ensure that they were understood and written correctly. The participants were also asked to indicate if there was anything they wanted to add to their statements. After analyzing all the data, the primary results were sent to the participants to be reviewed by them. Furthermore, to increase the transferability of the findings, it was attempted to select the appropriate samples at different levels of decision-making and implementation and to collect and analyze the data simultaneously (18). To follow the ethical codes and protect the participants' rights, the researcher introduced himself/herself, clearly explained the objectives of the study, obtained their oral consent, and assured them that the interviews would be kept confidential and unnamed.

\section{Interview Method}

Data collection was performed based on semi-structured interviews with open-ended answers and the least possible questions using a digital tape recorder. The questions were designed to reflect the views of the experts, pundits, policy-makers and planners involved in tackling COVID-19. All the interviews were 
conducted face-to-face by a researcher (19). Before the interview, the time and place of the interview were announced to the participants and an interview guide and purpose of the interview were sent to them via email. The participants' consent for recording the conversation was obtained at the beginning of the interview. In case that the conversation was not allowed to be recorded, notes were taken during the interview. Out of 32 interviews, only one interview was not allowed to be recorded and it was done through taking the notes. The researcher had an alternative tape recorder to prevent the probable unwanted problems. A time range of 35 to 90 min was selected for the interviews. At the end of each interview, the researcher encouraged the participants to freely express their feelings by asking them if they wanted to add anything else to their views. The interviews continued until reaching the data saturation stage(20).

\section{Features Of Babol City}

Babol, with a population of 530,000 , is one of the most important religious cities in the north of Mazandaran province. Since the cities in this province are close to each other and contain many transit routes, these cities usually face a heavy daily traffic. Babol is known as the first city of Mazandaran province holding a Medical Sciences university since 1983. Therefore, a large number of medicine specialists are currently working in various fields of medical sciences in this city. Babol is located between the Caspian Sea and the Alborz mountain range, at distances of $15 \mathrm{~km}$ and $211 \mathrm{~km}$ from the Caspian Sea and Tehran (the capital of Iran) respectively. The city, due to its temperate climate, green forests, and proximity to the Caspian Sea, is considered as a tourist-friendly city and the second home for Tehran dwellers.

\section{Results}

After several rounds of revision, the interviews and documents related to the policies were labeled and classified into five main themes (policy context, policy analysis, policy process, actors and stakeholders, and ways to deal with COVID-19) according to the Walt and Gilson's policy triangle framework. Each theme was divided into different sub-themes, and finally, the related topics were extracted from the subthemes (Table 1). 
Table 1

The extracted themes and sub-themes concerning COVID-19 policies

\begin{tabular}{|c|c|c|c|}
\hline No & Theme & Subtheme & Issues \\
\hline \multirow[t]{8}{*}{1} & \multirow[t]{8}{*}{ Policy Context } & \multirow{4}{*}{$\begin{array}{l}\text { Political } \\
\text { Factors }\end{array}$} & 1. The structure of political power \\
\hline & & & 2. Sanctions \\
\hline & & & 3. Political structure \\
\hline & & & $\begin{array}{l}\text { 4. Lack of adjustment between policies and livelihood of } \\
\text { people }\end{array}$ \\
\hline & & \multirow{2}{*}{$\begin{array}{l}\text { Economic } \\
\text { Factors }\end{array}$} & 1. A completely commercial city \\
\hline & & & $\begin{array}{l}\text { 2. Provision of personal protective equipment by non- } \\
\text { governmental organizations (NGOs) }\end{array}$ \\
\hline & & Social Factors & 1. Having a multidimensional cultural system \\
\hline & & $\begin{array}{l}\text { Cultural and } \\
\text { Religious } \\
\text { Factors }\end{array}$ & 1. Having a religious and traditional morale \\
\hline \multirow[t]{12}{*}{2} & \multirow[t]{12}{*}{ Policy Content } & \multirow{4}{*}{$\begin{array}{l}\text { Policy } \\
\text { Framework }\end{array}$} & 1. Lack of solid evidence and its use in policy-making \\
\hline & & & 2. Lack of specific regulations and instructions \\
\hline & & & $\begin{array}{l}\text { 3. The first academic experiences to tackle with the } \\
\text { COVID- } 19 \text { crisis in the country }\end{array}$ \\
\hline & & & 4. Lack of governmental funding \\
\hline & & \multirow[t]{8}{*}{ City Structure } & 1. Having a Medical Sciences university in the city \\
\hline & & & 2. Having 6 educational and medical centers \\
\hline & & & $\begin{array}{l}\text { 3. Having about } 360 \text { faculty members in basic sciences } \\
\text { and clinical sciences departments }\end{array}$ \\
\hline & & & $\begin{array}{l}\text { 4. Having an experienced nursing staff with non-invasive } \\
\text { training and work experience of } 15 \text { years }\end{array}$ \\
\hline & & & 5. Having ICU specialists \\
\hline & & & $\begin{array}{l}\text { 6. Presence of a centralized crisis committee and reliance } \\
\text { on a governmental institution }\end{array}$ \\
\hline & & & $\begin{array}{l}\text { 7. Relatively high income of people due to economic } \\
\text { activities }\end{array}$ \\
\hline & & & 8. Tourist and transit features \\
\hline
\end{tabular}




\begin{tabular}{|c|c|c|c|}
\hline No & Theme & Subtheme & Issues \\
\hline & & \multirow{7}{*}{$\begin{array}{l}\text { Nature of } \\
\text { COVID-19 }\end{array}$} & 1. Need for home and urban insulations \\
\hline & & & 2. Reducing traffic \\
\hline & & & $\begin{array}{l}\text { 3. Observing social distance to reduce the virus } \\
\text { transmission chain }\end{array}$ \\
\hline & & & 4. High incidence rate and frequency of infection cases \\
\hline & & & 5. Difficulty in identifying the virus carriers \\
\hline & & & $\begin{array}{l}\text { 6. Difficulty in identifying the infected people at early } \\
\text { stages }\end{array}$ \\
\hline & & & 7. High impact on people's lifestyle \\
\hline & & \multirow{2}{*}{$\begin{array}{l}\text { Non- } \\
\text { governmental } \\
\text { Organizations } \\
\text { (NGOs) }\end{array}$} & $\begin{array}{l}\text { 1. Diligent cooperation in the implementation of } \\
\text { programs }\end{array}$ \\
\hline & & & $\begin{array}{l}\text { 2. Assisting in monitoring the implementation of } \\
\text { activities and policies }\end{array}$ \\
\hline \multirow[t]{10}{*}{3} & \multirow[t]{10}{*}{ Policy Process } & Policy Agenda & $\begin{array}{l}\text { 1. Hospitalization of a theology student (resident of Qom) } \\
\text { with COVID-19 }\end{array}$ \\
\hline & & \multirow{9}{*}{$\begin{array}{l}\text { Policy } \\
\text { Formulation }\end{array}$} & 1. Selecting Yahya Nejad Hospital as a referral hospital \\
\hline & & & 2. Setting up a laboratory to perform PCR tests \\
\hline & & & 3. Setting up 16 - and 24 -hour clinics \\
\hline & & & 4. Converting some pharmacies into 24 -hour pharmacies \\
\hline & & & $\begin{array}{l}\text { 5. Giving licenses to several factories to produce gloves } \\
\text { and face masks }\end{array}$ \\
\hline & & & $\begin{array}{l}\text { 6. Holding virtual education classes for students, except } \\
\text { for interns and residents }\end{array}$ \\
\hline & & & $\begin{array}{l}\text { 7. Establishing aCOVID-19 crisis committee in the } \\
\text { university }\end{array}$ \\
\hline & & & $\begin{array}{l}\text { 8. Holding the regular meetings of the university crisis } \\
\text { committee concurrently with the city crisis committee }\end{array}$ \\
\hline & & & $\begin{array}{l}\text { 9. Establishing a COVID-19 national committee by the } \\
\text { clinical treatment group }\end{array}$ \\
\hline
\end{tabular}




\begin{tabular}{|c|c|c|c|}
\hline No & Theme & Subtheme & Issues \\
\hline & & \multirow{8}{*}{$\begin{array}{l}\text { Policy } \\
\text { Implementation }\end{array}$} & 1. Closing the student dormitories \\
\hline & & & 2. Developing virtual education for students \\
\hline & & & $\begin{array}{l}\text { 3. Holding several workshops of "producing e-learning } \\
\text { content" for university professors }\end{array}$ \\
\hline & & & 4. Organizing daily meetings of the crisis committee \\
\hline & & & $\begin{array}{l}\text { 5. Launching } 44 \text { care teams at urban and rural health } \\
\text { service centers }\end{array}$ \\
\hline & & & $\begin{array}{l}\text { 6. Performing the burial of bodies according to the health } \\
\text { protocol }\end{array}$ \\
\hline & & & $\begin{array}{l}\text { 7. Launching a dispatch system for answering the } \\
\text { people's questions by phone and educating them by } \\
\text { faculty members of the nursing and midwifery } \\
\text { department }\end{array}$ \\
\hline & & & $\begin{array}{l}\text { 8. Preparing a convalescent home when the hospital } \\
\text { beds are full }\end{array}$ \\
\hline & & \multirow{4}{*}{$\begin{array}{l}\text { Policy } \\
\text { Evaluation }\end{array}$} & 1. Reducing the chain of infection \\
\hline & & & 2. Reducing the hospitalization cases \\
\hline & & & 3. Reducing the number of deaths \\
\hline & & & 4. System resilience \\
\hline \multirow[t]{7}{*}{4} & \multirow[t]{7}{*}{ Actors } & Policy-makers & 1. Babol University of Medical Sciences \\
\hline & & \multirow{2}{*}{$\begin{array}{l}\text { Implementing } \\
\text { Organizations }\end{array}$} & 1. Babol University of Medical Sciences \\
\hline & & & 2. City crisis committee \\
\hline & & People & 1. Population of urban and rural residents \\
\hline & & \multirow{3}{*}{$\begin{array}{l}\text { Treatment } \\
\text { Staff }\end{array}$} & 1. Paramedical staff \\
\hline & & & 2. Doctors \\
\hline & & & 3. Nurses \\
\hline \multirow[t]{2}{*}{5} & \multirow[t]{2}{*}{$\begin{array}{l}\text { Strategies to } \\
\text { reduce the } \\
\text { incidence of } \\
\text { Covid-19 }\end{array}$} & $\begin{array}{l}\text { Improving the } \\
\text { Policy } \\
\text { Framework }\end{array}$ & $\begin{array}{l}\text { 1. Coordination between the service provider organization } \\
\text { and the health protocol monitoring organization }\end{array}$ \\
\hline & & $\begin{array}{l}\text { People's } \\
\text { participation }\end{array}$ & 1. Changes in people's behavior \\
\hline
\end{tabular}

\section{Policy context}


Various factors played a role of underlying factor in policy responses of BUMS to COVID-19. The factors including political factors, economic factors, social factors and cultural and religious factors were extracted by summarizing the opinions expressed by the interviewees. The findings indicated that lack of an appropriate platform for administrative actions and unimplementation of the infrastructure and administrative requirements were among the most important factors preventing the full implementation of the policy responses of BUMS to COVID-19.

\section{A. Political factors}

Policy outcomes are not always sufficiently relevant to the policy objectives (21). The interviewees stated that hierarchical control of the execution process was difficult and unfavorable execution conditions led to complete failure. Effective execution required a chain of commands and capacities for coordination and control which were absent. The first political factor is the political structure of power, implying that power is not integrated and is exerted by different sectors (22). Some of the executive organizations which could play a significant role in implementing the policies did not act forcefully because the full implementation of the policies was correlated with the people's livelihood. Analysis of the interview data and documents showed that the rules were not too strict to harm the low-income strata and create severe restrictions on society. One of the interviewees said:

"I think there was no potential for exerting legal actions by the monitoring and prevention systems. Therefore, this part of the monitoring job was not correctly rendered at the society. They did not define a specific mechanism, and did not enact a written law for that matter. For example, the COVID-19 crisis committee did not fine a person who did not wear a face mask." (internal specialist)

Knowing that Iran is under the heavy international sanctions, the lack of financial resources and provision of personal protective equipment and medicines were the main problems for full implementation of the policy responses of BUMS to COVID-19.

\section{B. Economic factors}

Most of the people in the study area make their living by trading. Hence, the people had a good financial condition, which is why in the first phase of the crisis, when the city was suddenly stricken by the COVID19 crisis, they had a good resilience.

"Babol is the economic center of Mazandaran province, which was formerly called "Barforoush" (seller) meaning that it was a hub for most of the economic activities in the province. People are rich and we should not compare them with the people in other provinces. In this way, they contributed to providing the personal protective equipment which was necessary for patients and medical staff." (infectious disease specialist)

Although the medicines used for the treatment of the hospitalized patients with COVID-19 were very expensive, they were completely free for the patients. In this case, one of the interviewees said: 
"The cost was completely free. Once the national decision-makers said that the treatment of the patients with COVID-19 should not be free, but we did not follow this directive at our own risk." (internal specialist)

\section{Social factors}

The experts believed that the social system in Iran was not based on a monocultural or one-dimensional system, and it rather contained the multicultural individuals with multiple subcultures. For this reason, the reference points were culturally and socially diverse. One of the experts admitted:

"We have a system which contains multiple subcultures and a multifaceted cultural system in which the people have different gathering places. Today they go to a wedding or mosque and tomorrow they go to the stadium." (anesthesiologist)

Considering the nature of the COVID-19 virus, the people's beliefs had a great impact on its control. Overcoming the psychological limitations at the onset of the COVID-19 virus outbreak considerably contributed to its control.

\section{Cultural and religious factors}

Culturally, gathering of people is very common in the study area. Since the whole city were to celebrate the Persian new year (Nowruz), it was difficult to keep them under control. Furthermore, due to the people's religious beliefs, many religious gatherings and ceremonies were held in the city. Nevertheless, these gatherings and ceremonies were changed to some extent, as some of the interviewees said:

"Religious groups, even the theology students, came to the hospital and took part in transporting the patient and oxygen. The religious groups came and allocated the budgets of their religious gatherings to fulfill the needs of the patients with COVID-19, and we were able to buy four suction devices. In fact, the budgets for religious ceremonies were directed towards the COVID-19 crisis treatment." (internal specialist)

"Actually, one of the good measures taken by the COVID-19 crisis committee at the county and provincial levels was making decision equally for religious and non-religious institutions, sport centers and markets. It wasn't like to say that because a religious institution is powerful, it is an exception and it can hold its religious ceremonies, or because our economy depends on market, one can go and open his store; no, it was not like that. Most of the decisions were made by experts. Rarely it was seen that a few institutions or people did not act properly, and they were improved over time." (environmental health specialist)

"The culture of the people in Babol is higher than those in other cities of the province, at least at the scientific level. The people noticed the situation, but the general atmosphere and the false news misled them and potentially encouraged them not to observe the protocols as expected. The public media and cyberspace, in some cases, sent the message that things were not that serious. The WHO itself sent the big wrong message that the face mask had not enough coverage and it should be used only in medical 
centers but not in the public. This contradiction made us experience several pandemic peaks." (infectious disease specialist)

\section{Policy content}

The policy content clarifies that: Which policy is better? Which health services should be omitted? Which policy tools are needed? Who makes and implements the decisions? (23). Policy analysis is designed to better understand the policy process and to provide the policy-related knowledge and evidence on economic and social problems. The information produced in this way can be used in the policy-making process to solve the policy problems (15).

\section{A. Policy framework}

BUMS was among the first universities to suffer from the crisis in the first week of the virus entering the country. People became infected, and since it was the first appearance of the COVID-19 crisis in the country and the resources were limited, everything was ambiguous for the people and the BUMS medical staff at first. At that time, there was no strong evidence against COVID-19, and no specific regulations and guidelines had been formulated for it. The first ministerial chart reached the BUMS on 23 February. Therefore, the university officials were could rapidly overcome their psychological limitations, and the COVID-19 crisis committee was formed in the university. This committee was hold at the presence of the supply council, the city governor and the medical staff, in which the prevention and treatment policies were adopted. To prevent the spread of the disease, the university asked for help of the authorities governing the city. Since, at that time, the people living in the city were to celebrate Nowruz and many local markets were open, the COVID-19 crisis committee with the help of the supply council could prevent the opening of the market. One of the interviewees said:

"Another strength of the university was to engage various executive departments of the city, even the district governors, Basij, theology students, and anyone we thought could help us in this epidemic. We engaged everyone. The markets were closed, which was quite helpful. Even at the last days of the year, when people normally go shopping for the new year, the market was actually closed. This was achieved with the help of the guilds, the governorship, and the police. We controlled the taxis and the cafés and the hookah bars were all closed. A large number of public places were sealed by the health center and the police. If these measures were not taken, we would face unprecedented casualties in the first peak, and we would have a greater struggle with the disease, whether we like it or not." (environmental health specialist)

\section{B. City structure}

Babol has one medical sciences university, which includes six teaching hospitals, two private hospitals, over 360 faculty members, ICU specialists, lung specialists, internal medicine specialists, several infectious disease specialists, pharmacists, environmental health specialists, epidemiologists, and 
experienced nursing staff, with "non-invasive" trainings and 15 years of work experience, who could substantially support the services. One of the interviewees declared:

"In this situation, the expert nurses worked very hard, and we should truly value the position and the role of the nurses higher than the doctors. A doctor gives the orders only once, but that's the nurse who performs the work and observes the patient all the time. Finally, the nurse solves the problems and accomplishes the job. In brief, the nurses work from the bottom of their heart. (infectious disease specialist)

The people with high income and the good behavioral process adopted by the university committee to govern the hospitals were among the privileges of Babol. Another feature of Babol is its transit route. Since the cities of Mazandaran province are very close to each other, many people commute daily from other cities to this city to attend their workplace or go shopping. Another feature of the city is its pleasant weather, which attracts many people from south and east of Iran. significantly, entrance of the citizens of Tehran due to the two-week shutdown at the first peak of COVID-19 was one of the major issues that increased the traffic in the city.

\section{Nature of the COVID-19 virus}

The interviewees acknowledged that, during the past 10 to 15 years, the policies of the university have focused on non-infectious diseases such as cancer and cardiovascular disease. In fact, they were unaware of some types of infectious disease because they did not lead to considerable mortality. The only common infectious disease was the H1N1 flu which was simply controlled. The older versions of COVID-19, namely SARS-CoV and MERS-CoV, practically did not affect Iran or they had a very low incidence. Therefore, they did not have any related experiences, in terms of either laboratory or imaging. However, the nature of the COVID-19 virus showed that it could not be controlled only by the medical staff alone. In fact, it was necessary to reduce the traffic, set up home isolation in case of infection, and observe the social distance to break the chain of infection. The virus had a great impact on people's lives due to its high incidence, high frequency of the infected cases, and unidentifiability of the carriers. One of the interviewees stated:

"To succeed in controlling the virus, we should consider three items: the triple-T strategy (which stands for targeting, testing, and tracking), contact tracing, and treatment. BUMS did very well in testing and treatment from the beginning of the fight against COVID-19. We launched the PCR diagnostic test laboratory on March 7, 2020. This means that we set up this laboratory much earlier than other medical sciences universities in the country. Nevertheless, the most important issue was contact tracing which was not properly performed neither in BUMS nor in other parts of Iran."(virologist)

"After one week, the statistics rose to an extent that, for example, we had 50 to 60 inpatients a day, occupying all the hospital beds in three days. Therefore, we needed to establish another hospital. This amount of inpatients in such a short period had not been seen in Iran or any other country in the world. Our hospitalization rate even reached 110 patients a day." (infectious disease specialist) 
Considering the place where the first case of COVID-19 appeared and the points where it unofficially spread in the country, the interviewees stated that the researchers had not given them any information. However, according to the official declarations, the first chains of infection started from Qom, Tehran, Guilan and Babol. All these events occurred in our country within two weeks. In other words, Babol was among the cities which were affected by the crisis in the first weeks of the virus arrival in the country, and its citizens were infected.

\section{NGOs and donors in the city}

Experts acknowledged that the Babol Health Charity Foundation, a voluntary non-governmental organization, played an important role during the COVID-19 crisis and covered about one-seventeenth of the treatment costs. This foundation, as a link between donors and the university, acted systematically and played a very important role in providing personal protective equipment, pulse oximeter, oxygen generator, CPAP, Bipap and even the food required for the medical staff. One of the interviewees expressed:

"The donors provided us with very good protections. In the turbulent situation in March, the donors helped the patients by providing them with medicines. The people spent at least $\$ 2,000$ to buy IVIG, which was later shown to have little effect, without being sure about its efficiency. Meanwhile, the donors were really determined and stayed with us at the hospital, and thereby we could manage the situation in that crucial condition." (infectious disease specialist)

\section{Policy-making process}

The policy-making process is rarely a clear procedure. The problem may be identified in the first step, or the policy may never be implemented. The policy-making process is usually very complex. There are many actors, including stakeholders, governmental agencies, political parties, the media and the research community, with different values and goals and different perceptions of reality and policy preferences. Thus, the goal of policy-making is to align different perspectives (24). This means that policy-making cannot be performed solely by relying on evidence. In fact, none of the political decisions can be determined by evidence alone, because judgments, values and other factors, such as political knowledge and professional experience of different people, are always involved in this process $(25,26)$. Policymaking is a process of formulation, implementation and evaluation of the different decisions and policies adopted by official and unofficial decision-makers and has direct and indirect effects on people's lives (27).

\section{A. The policy agenda of COVID-19 crisis}

All the participants acknowledged that the crisis code was announced in Babol after hospitalization of a theology student from Qom, who had symptoms of COVID-19. One of the interviewees explained:

"For the first time, the infectious diseases resident reported a patient with critical condition, who was a theology student from Qom. At the same time, the disease spread in Qom. I checked his CT scan and 
found that they were compatible with his symptoms. At the beginning, the infected cases were two to three persons a day, but they significantly increased within a week, due to some factors such as social gatherings." (infectious disease specialist)

Therefore, the crisis code was announced by BUMS in Babol on February 20, 2021.

\section{B. Developing and adopting policies}

To deal with COVID-19 in terms of reducing the incidence and treatment of the hospitalized patients, BUMS established the COVID-19 crisis committee. The COVID-19 crisis committee meetings were held daily during the first peak of the crisis. According to the instructions of the Ministry of Health, one of the hospitals was assigned as a referral hospital for the patients with COVID-19. Since Yahya Nejad Hospital had been previously used for the patients with $\mathrm{H} 1 \mathrm{~N} 1 \mathrm{flu}$, it was selected for this purpose. However, all the beds of Yahya Nejad hospital become full within three days and inevitably a section of Rouhani hospital was dedicated to the patients with COVID-19. To identify the patients before they reach an acute stage, they were required to be diagnosed in early stages. Therefore, the COVID-19 crisis committee decided to use one of the university laboratories for PCR diagnostic test and establish 16- and 24-hour clinics. A private laboratory and a round-the-clock radiology center were also employed to help the governmental sector. To prevent overcrowding in pharmacies on night shifts, some pharmacies were allowed to be open around the clock. Moreover, some factories of the city were licensed to produce adequate personal protective equipment, such as gloves, face masks, and disinfectants, to meet the demands of the people. Lessons of the students, except for medical interns and residents, was taught using the virtual education tools.

\section{C- Policy implementation}

Student dormitories were closed to control the disease, and several "virtual education content production" workshops were held for university professors. 44 care teams were organized at the urban and rural health service centers. Burials were done according to the protocol. A dispatch system was used to answer the people's questions and train them with the help of the university faculty members. Moreover, some volunteers were train to support the hospital. A convalescent home was put on standby to be used when the hospital beds were full. One of the interviewees said:

"We used to move the crisis committee to the target places which had the infection. That is, the crisis committee was called the crisis committee of the university, but when Yahya Nejad hospital, for example, turned into an admission center, the crisis committee was transferred there for 10 days. In fact, the city and university officials used to come to Yahya Nejad hospital to solve the problems. Then, we went to Rouhani hospital and the crisis committee moved there. This trend continued until the crisis in the city reached a stable condition and the methods for dealing with the disease reached a mature level. Since then, the meetings of the crisis committee were held at the university." (internal medicine specialist) 
As of March 5, there was no specific national or global protocol to combat COVID-19. One of the interviewees added:

"At first, there was a lot of confusion about choosing the right protocol when the COVID-19 pandemic started. Everyone was writing his own prescription and it was confusing. At early stages, medications had to be taken based on clinical trials. There was not enough time to test them on patients. We gave the patients Kaletra, Tamiflu, Hydroxychloroquine, IVIG, Plasma therapy and whatever we could, because we were really confused. At first, a very primitive national protocol was issued that provided a brief guide for professors and those involved in COVID-19 on how to manage the disease. It was like a roadmap, but it was not what we really needed. Since drug interactions were not taken into account, we had a high rate of mortality due to giving multiple drugs. Maybe it was because of the virus itself, or the prescribed medicationor even the patients who used to attend the hospital at the final stages of the disease. Mortality was very high in late February and early March." (lung specialist)

Therefore, members of the subspecialty board (ICU, lung and internal medicine) and infectious disease specialists at Rouhani hospital came together to integrate the treatment and formed the national COVID19 crisis committee.

"A protocol was developed based a series of our own studies on the European and American guidelines and the experiences of professors. (see Additional file 4) After the implementation of this protocol, the situation improved. We realized what treatments to give, what drug interactions may happen, to whom we should give medications or to whom we shouldn't, whom to send to the ICU, for which patient to start oxygen therapy, when to start BiPAP, when to intubate the patient, when to give antibiotics, to whom we shouldn't give antibiotics, and what tests to prescribe. Well, based on studies, we found out that pathology of the virus is micro-thrombosis. So, we started the anticoagulant treatments and asked for help of the cardiologists." (lung specialist)

The volunteers in the city were invited and employed to set up a convalescent home.

\section{Policy evaluation}

Analysis of the findings showed that BUMS, aided by the city authorities and the volunteered people, could significantly reduce the rates of hospitalization, positive PCR and mortality by implementing the policies for fighting COVID-19 for two months (from February 20 to April 20). This condition continued for one month, the positive PCR samples were largely reduced and even reached zero in some days. At this time, the people's fear of the epidemic was reduced. Due to certain problems associated with quarantine in the country, the health protocols were loosely followed. Most of the people concluded that the epidemic was controlled. Some deficiencies in commitment to prevention were also observed in some governmental institutions and in BUMS in following the formulated policies. Opening of wedding venues, schools and religious institutions was a sign of neglecting the social distance. This led to the second peak. One of the interviewees believed: 
"In particular, I think a common characteristic of us is that we do well when we are under maximum pressure. The problem has been exacerbated probably due to the fact that the pressure has been removed to some extent. If we still had the perseverance of those days, we would have less problems today. One of our weaknesses is that we work well under maximum pressure. I think, under medium to low pressures, our procrastination emerges and our weaknesses become more apparent." (internal medicine specialist)

From the third week of May, the number of hospitalizations raised to even more than the number of hospitalizations in the first peak, and reached the highest level in the third week of July (Figure 1). However, the rate of mortality was lower compared to the first peak. In this regard, one of the experts admitted:

"The most important reason was mutation of the virus, which strengthened its infectivity and reduced the severity of the disease at the same time. We observed an increase in the severity of the disease in late February and early March. The enhanced awareness in the people and doctors was very helpful. We gained more experience and we could select the patients and identify the acute cases much easier. Our fears about giving a large amount of drugs to the patient and our doubt about the effectiveness of drugs had been greatly reduced. The significantly increased experience of the health system led to the reduction of the mortality rates. The hospitals were more prepared, the ICUs were much better equipped, and the issues related to oxygen and other problems in the hospitals were almost eliminated. All of these factors reduced the mortality rates." (infectious disease specialist)

As shown in Figure 1, Babol experienced the third peak in the fourth week of January, 2021.

\section{Policy actors and stakeholders}

Making the right decision requires awareness about the mechanisms that contribute to the efficiency of policy-making. It is not expected that policy-makers, regardless of the factors influencing the policymaking process (including stakeholders), formulate policies for the health system. To face these challenges, taking advantage of the different policy-making theories and patterns in policy analysis helps the policy-makers pass through the superficial layer of policy analysis and reach the deeper layers of the complex health system policies and gain a comprehensive understanding of the target policies (28).

\section{A. Policy-makers}

After hospitalization of a patient with symptoms of COVID-19 in one of the hospitals, the COVID-19 crisis committee was formed in BUMS. This committee consisted five working groups as care and treatment, prevention and health, epidemiology, support, and public relations working groups. Each working group had specific tasks.

"The only working group which permanently performed its duty, boarded the boat, took the oar, and set oft was the care and treatment working group." (internal medicine specialist)

\section{B. Administrative organizations}

Page $16 / 24$ 
As an administrative organization, BUMS mainly focused on care and treatment of the patients with COVID-19, while the city organization bodies focused on preventive policies such as controlling the traffic and gatherings and spraying the disinfectants.

\section{People}

Since spread of the virus has a direct relationship with social distancing and lower traffic, the people can be considered as one of the main factors in controlling the COVID-19 virus. One of the experts confirmed:

"Unofficial propaganda supported the belief that it would be better for a person with primary symptoms not to go to the hospital. Therefore, long delays in going to the hospital made the treatment more difficult for doctors." (ICU specialist)

\section{Medical staff}

Safety of the medical staff, particularly nurses, had an important role in controlling the COVID-19 virus. If nurses were infected with COVID-19, their quarantine for two weeks and substitution of their shifts would impose many difficulties to the directors of the hospitals.

"Knowing that more than $80 \%$ of the medical care process is done by nurses, at the beginning of the pandemic, many of them were afflicted with severe anxiety and obsessive-compulsive disorder. The next problem was their breakroom which was not standard. Under these circumstances, if a nurse became infected, he/she could infect others in a short time. About 75\% of the nurses were infected, but fortunately we did not have any mortality among the nurses." (infectious disease specialist)

\section{Strategies to reduce the number of patients with COVID-19}

The experts believed that tackling COVID-19 required an integrated management to coordinate the service providers and related institutions.

\section{A. Improving the policy framework}

Normally, BUMS shall not be responsible for infection control in the city, and hospital should not be the main place for fighting the disease. In fact, all the institutions which have power must be responsible for dealing with COVID-19. One of the experts admitted:

"If these 530,000 people along with the population of the nearby cities were to be hospitalized and we had to admit the patients until the last minute, we would be defeated by the crisis. So, we required the collaboration of other institutions to logically pass this stage and break the chain of infection." (internal medicine specialist)

\section{B. People's participation in observing the protocols}


People's participation is the most important factor in defeating COVID-19, and they can break the chain by changing their behavior such as reducing their interpersonal relationships and avoiding the collective activities and gatherings.

\section{Discussions}

With identification and registration of the first COVID-19 patient in Babol, it was officially included in the COVID-19 regions of the country on February 20, 2020 (2). Due to the fact that the outbreak of the disease was very unexpected, the infodemiology indices failed to enhance the readiness of health care systems in the study area (29). At first, the atmosphere was very stressful and everyone needed to be mentally and emotionally strengthened (30). Health promotion and disease prevention require the actions of different levels of the society. Normally, the government and other institutions and organizations are responsible to take such actions. The factors related to health functions in the society have turned the health policy analysis into an important issue. Thus, the policy analysts should find some ways to simplify the situation for policy analysis in the health system. This involves formulation of a theoretical framework that can determine the significant and insignificant factors and relationships (15). The important related factors were: overcoming the limitation of financial resources, providing the necessary facilities to deal with COVID-19, informing the people and their participation in adhering to the protocols, overcoming the psychological limitations, recognizing the disease, and discovering the methods of treatment. In the given conditions, it was necessary to postpone the development plans of the university and temporarily ignore the revenue generation of the hospitals for a while. Policy is a key concept through which the communities are organized and managed. Most of the policy consequences do not only involve the decisions on why and how to act, but also contain the guidelines on how to allocate the resources to support the implementation of policies and their consequences (8). The first and the biggest problem at the beginning of the COVID-19 crisis was the lack of oxygen supply for patients in one of the hospitals. The oxygen generator device was provided by the donors in less than three days. Thus, the cooperation of the donors with the decision-makers and executives of the health system encouraged the medical staff to continue the course of treatment with more strength.

Pan et al. (2020) conducted a study based on which a series of multifaceted public health interventions (social distancing, traffic restrictions, staying home, and centralized quarantine) temporarily improved the control of COVID-19 outbreak in Wuhan, China (31). The government intervened (two-week shutdown) in late February and early March in Iran and asked the people to stay home. However, the citizens of Tehran ignored the warnings and went to the northern cities of the country, especially Babol. This plan could not contribute to breaking the chain of infection. Since no national, provincial or local traffic laws were enacted, movement of the people remained as one of the obvious challenges in controlling the pandemic. In cases of rapid change and fundamental uncertainty, the policy-makers should consider future opportunities. The use of strategic foresight tools is essential for establishing better policies (32).

One of the strengths of the city was the presence of a medical sciences university in it. Therefore, the medical measures started from the very beginning and gradually became more disciplined by formation 
of the national COVID-19 crisis committee composed of the ICU, lung, heart and internal medicine specialists as well as the infectious disease specialists, virologists, environmental health specialists and epidemiologists. Full prevention, which required the cooperation of different institutions, was not done systematically and remained as one of the weaknesses in dealing with COVID-19. The patients with a positive COVID-19 test who had no indication for hospitalization were released into the society and their contacts could not be traced. Studies have shown that among the few weapons for fighting COVID-19, contact tracing can be the most powerful case (33). Since the physicians and nurses used to practice according to protocols, in the absence of a specific treatment protocol for COVID-19, they were subjected to moral injury because they did not exactly know, for instance, at what blood oxygen level the patient would require intubation. Although the new treatments and drugs were introduced in different countries at that time, none of them were guaranteed. Therefore, the ICU, pulmonary, internal medicine, infectious and cardiac specialists formed a "committee of critically ill patients" in the hospital for better decisionmaking. Using the evidences in the world and the country and relying on the experiences they had gained, they established a localized protocol and attempted to manage the treatments and treat the critically ill patients with a higher certainty (34).

The limitation in the present study was difficulty in accessing some of the key individuals. Since the interviews were recorded by the researcher, the participants observed the conservatism in their speech, and during the interview, the researcher was careful not to push the interviewee to defend his or her position. One of the important rules in qualitative studies is management of bias. Therefore, the probable effect of the researchers' bias on the quality of the present study can be mentioned as one of the inherent limitations of such studies $(35,36)$.

\section{Conclusions}

The COVID-19 policy analysis at BUMS suggests that policy-makers and planners were initially faced with a large number of patients awaiting treatment. Therefore, most of the decisions, policies and programs were oriented towards taking care and treatment of the patients and providing them with services. Adhering to health protocols and infection prevention was at the second priority of policy formulation, and there was no explicit program or policy to track the asymptomatic carriers in the society.

\section{List Of Abbreviations}




\begin{tabular}{|llll|}
\hline COVID-19 & Coronavirus Disease & ICU & Intensive Care Unit \\
\hline $\begin{array}{l}\text { SARS- } \\
\text { CoV }\end{array}$ & $\begin{array}{l}\text { Severe Acute Respiratory Syndrome } \\
\text { coronavirus }\end{array}$ & PCR & Polymerase Chain Reaction \\
\hline $\begin{array}{l}\text { MERS- } \\
\text { CoV }\end{array}$ & $\begin{array}{l}\text { Middle East Respiratory Syndrome } \\
\text { Coronavirus }\end{array}$ & $\begin{array}{l}\text { CT } \\
\text { scan }\end{array}$ & Computed Tomography scan \\
\hline BiPAP & Bilevel Positive Airway Pressure & CDC & Centers for Disease Control \\
\hline CPAP & Continuous Positive Airway Pressure & NGOs & $\begin{array}{l}\text { Non-governmental } \\
\text { organizations }\end{array}$ \\
\hline BUMS & Babol University of Medical Sciences & WHO & World Health Organization \\
\hline IVIG & Intravenous Immunoglobulin & & \\
\hline
\end{tabular}

\section{Declarations}

\section{Ethics Approval and Consent to Participate}

The study was done after holding the ethical code of IR.MUBABOL.HRI.REC.1399.086 from Babol University of Medical Sciences. Written informed consent was obtained from all study participants.

\section{Consent for Publication}

Not applicable.

\section{Availability of Data and Materials}

The authors have full control over the primary data. The data analyzed in this study are housed at Social Determinants of health research center in Babol University of Medical Sciences, Ganjafrooz Square, Babol, Mazandaran, Iran. According to the ethical committee approval, this dataset is subject to ethical restrictions and local data protection regulations regarding qualitative raw data, since participant privacy could be compromised. All relevant data for the conclusions are presented in the manuscript.

\section{Competing interests}

The authors declare that they have no competing interests.

\section{Funding}

There was no financial support in the design of the study, data collection, analysis and interpretation of results and writing of the manuscript.

\section{Authors' Contributions}


$\mathrm{ZF}$ and MA $\mathrm{J}$ and $\mathrm{M} \mathrm{S}$ were the principal investigators and designed the study. ZF searched literature. Z F and MA $\mathrm{J}$ and $\mathrm{M} S$ supported the interview development. Z F collected data and prepared data for qualitative analyses. Z F and MA J and M S supervised data collection. Z F and MA J analyzed data. Z F drafted the manuscript and MA J supported drafting the manuscript. All authors have provided comments and critical revisions to the manuscript. All authors approved the final manuscript prior to submission.

\section{Acknowledgments}

We would like to thank the esteemed President of Babol University of Medical Sciences, and all the deputies, heads of educational and medical centers, faculty members, experts and health donors who helped us in compiling this collection.

\section{Authors' information (optional)}

\section{Conflict of interest}

The authors declare that there is no conflict of interest.

\section{References}

1. World Health Organization Coronovirus Disease(COVID-19). Dashboard.Overview. Accssess 12.20 pm CEST, 14 May 2021. https://covid19.who.int/? gclid=EAlalQobChMI2dStulvJ8AIVAp7tCh1jeQ4nEAAYASABEgLNCfD_BwE.

2. Raoofi A, Takian A, Sari AA, Olyaeemanesh A, Haghighi H, Aarabi M. COVID-19 pandemic and comparative health policy learning in Iran. Arch Iran Med. 2020;23(4):220-34.

3. Wang Y, Wang Y, Chen Y, Qin Q. Unique epidemiological and clinical features of the emerging 2019 novel coronavirus pneumonia (COVID-19) implicate special control measures. Journal of medical virology. 2020;92(6):568-76.

4. Cascella M, Rajnik M, Cuomo A, Dulebohn SC, Di Napoli R. Features, evaluation, and treatment of coronavirus (COVID-19). Statpearls [internet]. 2021.

5. Nicola M, Sohrabi C, Mathew G, Kerwan A, Al-Jabir A, Griffın M, et al. Health policy and leadership models during the COVID-19 pandemic-review article. International Journal of Surgery. 2020.

6. Fischer F, Miller GJ. Handbook of public policy analysis: theory, politics, and methods. Routledge; 2017.

7. Giannopoulou I, Tsobanoglou GO. COVID-19 pandemic: challenges and opportunities for the Greek health care system. Irish journal of psychological medicine. 2020;37(3):226-30.

8. Jain V, Duse A, Bausch DG. Planning for large epidemics and pandemics: challenges from a policy perspective. Curr Opin Infect Dis. 2018;31(4):316-24.

9. Weimer DL, Vining AR. Policy analysis: Concepts and practice. Taylor \& Francis; 2017. 
10. Mackenbach J, McKee M. Successes and failures of health policy in Europe: Four decades of divergent trends and converging challenges: Four decades of divergent trends and converging challenges. McGraw-Hill Education (UK); 2013.

11. Gilson L, Raphaely N. The terrain of health policy analysis in low and middle income countries: a review of published literature 1994-2007. Health policy planning. 2008;23(5):294-307.

12. Graneheim UH, Lundman B. Qualitative content analysis in nursing research: concepts, procedures and measures to achieve trustworthiness. Nurse education today. 2004;24(2):105-12.

13. Gale NK, Heath G, Cameron E, Rashid S, Redwood S. Using the framework method for the analysis of qualitative data in multi-disciplinary health research. BMC medical research methodology. 2013;13(1):1-8.

14. Walt G, Gilson L. Can frameworks inform knowledge about health policy processes? Reviewing health policy papers on agenda setting and testing them against a specific priority-setting framework. Health policy planning. 2014;29(suppl_3):iii6-22.

15. Dunn WN. Public policy analysis. Routledge; 2015.

16. Ghaffar A, Gilson L, Tomson G, Viergever R, Røttingen J-A. Where is the policy in health policy and systems research agenda? Bull World Health Organ. 2016;94(4):306.

17. Coveney J. Analyzing public health policy: three approaches. Health Promotion Practice. 2010;11(4):515-21.

18. Lincoln YS, Lynham SA, Guba EG. Paradigmatic controversies, contradictions, and emerging confluences, revisited. The Sage handbook of qualitative research. 2011;4:97-128.

19. Oltmann S. editor Qualitative interviews: A methodological discussion of the interviewer and respondent contexts. Forum Qualitative Sozialforschung/Forum: Qualitative Social Research; 2016.

20. Ritchie J, Lewis J, Nicholls CM, Ormston R. Qualitative research practice: A guide for social science students. and researchers: sage; 2013.

21. Schumann A. Using outcome indicators to improve policies: Methods, design strategies and implementation. 2016.

22. Geppert M, Dörrenbächer C. Politics and power within multinational corporations: Mainstream studies, emerging critical approaches and suggestions for future research. International Journal of Management Reviews. 2014;16(2):226-44.

23. Briggs DJ. A framework for integrated environmental health impact assessment of systemic risks. Environmental health. 2008;7(1):1-17.

24. Head BW. Three lenses of evidence-based policy. Australian Journal of Public Administration. 2008;67(1):1-11.

25. Choi BC, Anita W. Multidisciplinarity, interdisciplinarity, and transdisciplinarity in health research, services, education and policy: 3. Discipline, inter-discipline distance, and selection of discipline. Clinical and Investigative Medicine. 2008:E41-E8. 
26. Chalmers I. If evidence-informed policy works in practice, does it matter if it doesn't work in theory? Evidence \& Policy: A Journal of Research. Debate Practice. 2005;1(2):227-42.

27. Exworthy M. Policy to tackle the social determinants of health: using conceptual models to understand the policy process. Health policy planning. 2008;23(5):318-27.

28. Surjadjaja C, Mayhew SH. Can policy analysis theories predict and inform policy change? Reflections on the battle for legal abortion in Indonesia. Health Policy Plann. 2011;26(5):373-84.

29. Mavragani A. Tracking. COVID-19 in Europe: infodemiology approach. JMIR public health surveillance. 2020;6(2):e18941.

30. Anjum S, Ullah R, Rana MS, Ali Khan H, Memon FS, Ahmed Y, et al. COVID-19 Pandemic: A Serious Threat for Public Mental Health Globally. Psychiatria Danubina. 2020;32(2):245-50.

31. Pan A, Liu L, Wang C, Guo H, Hao X, Wang Q, et al. Association of public health interventions with the epidemiology of the COVID-19 outbreak in Wuhan, China. Jama. 2020;323(19):1915-23.

32. Cook CN, Inayatullah S, Burgman MA, Sutherland WJ, Wintle BA. Strategic foresight: how planning for the unpredictable can improve environmental decision-making. Trends Ecol Evol. 2014;29(9):531-41.

33. Garry M, Hope L, Zajac R, Verrall AJ, Robertson JM. Contact Tracing: A Memory Task With Consequences for Public Health. Perspectives on Psychological Science. 2020:1745691620978205.

34. Alkabba AF, Hussein GM, Albar AA, Bahnassy AA, Qadi M. The major medical ethical challenges facing the public and healthcare providers in Saudi Arabia. Journal of Family Community Medicine. 2012;19(1):1.

35. Benzies KM, Premji S, Hayden KA, Serrett K. State-of-the-evidence reviews: advantages and challenges of including grey literature. Worldviews on Evidence-Based Nursing. 2006;3(2):55-61.

36. Galdas P. Revisiting bias in qualitative research: Reflections on its relationship with funding and impact. Los Angeles: SAGE Publications Sage CA; 2017.

\section{Figures}




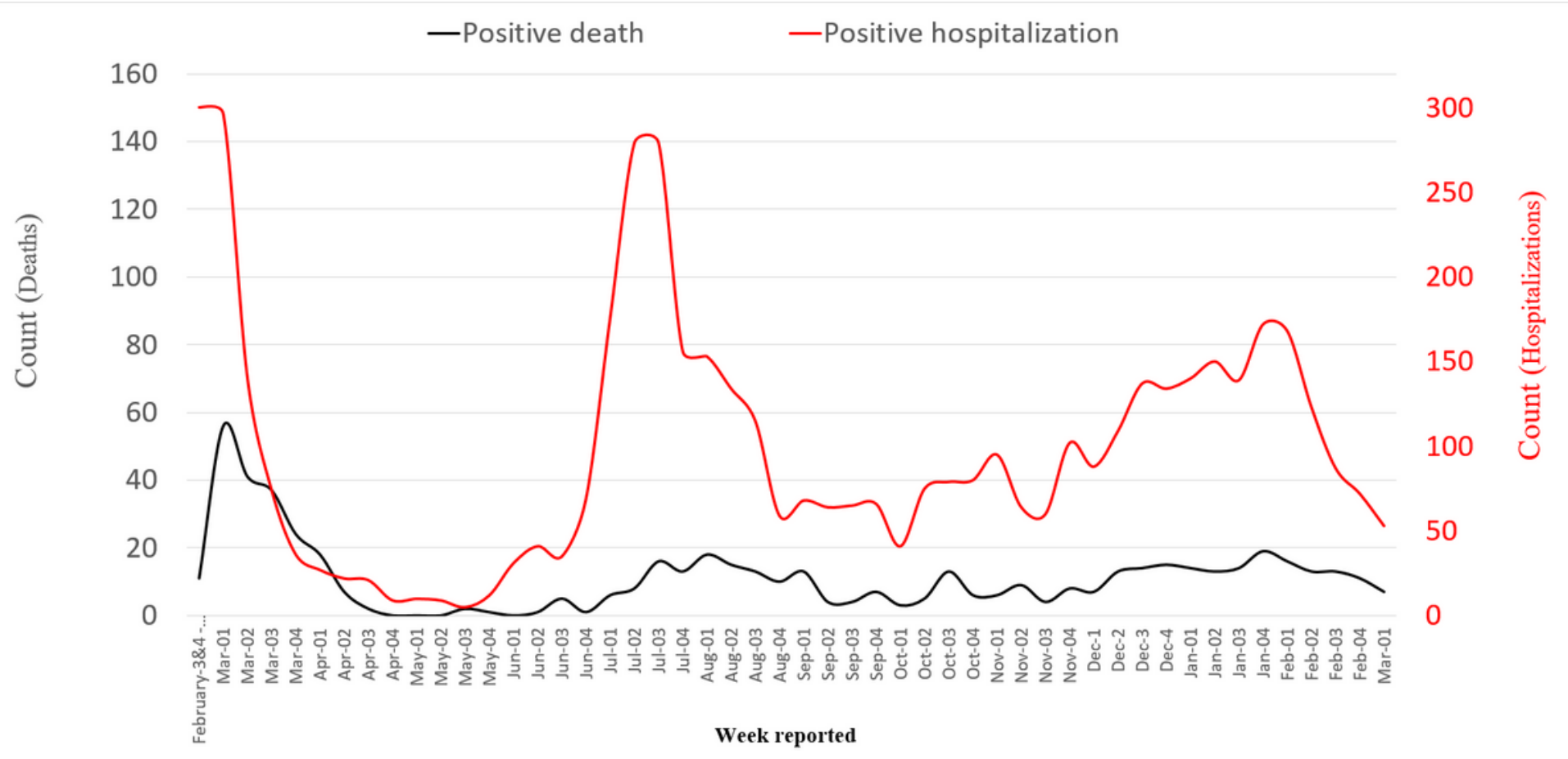

Figure 1

The trend of hospitalization cases, positive PCR and mortality in Babol from February 20, 2020 to March 7, 2021

\section{Supplementary Files}

This is a list of supplementary files associated with this preprint. Click to download.

- Additionalfile1.docx

- Additionalfile2.docx

- Additionalfile3.docx

- Additionalfile4.docx

- checklistreportingqualitativeresearchCOREQ.docx 